\title{
Knowledge and Attitude of Primary School Teachers in Tehran/Iran towards ADHD and SLD
}

\author{
Mojgan Khademi ${ }^{1}$, Sepideh Rajeziesfahani ${ }^{2}$, Simasadat Noorbakhsh ${ }^{2}$, Leili Panaghi ${ }^{3}$, Rozita Davari-Ashtiani ${ }^{1}$, \\ Katayoon Razjouyan ${ }^{1} \&$ Nina Salamatbakhsh ${ }^{2}$ \\ ${ }^{1}$ Child and Adolescent Psychiatry, Shahid Beheshti University of Medical Sciences, Tehran, Iran \\ ${ }^{2}$ Behavioral Sciences Research Center of Shahid Beheshti University of Medical Sciences, Tehran, Iran \\ ${ }^{3}$ Community Medicine Shahid Beheshti University, Tehran, Iran \\ Correspondence: Nina Salamatbakhsh, Behavioral Sciences Research Center of Shahid Beheshti University of \\ Medical Sciences, Tehran, Iran. Tell/Fax: 98-21-7755-3074. E-mail: n.salamatbakhsh@gmail.com
}

Received: February 24, 2016

Accepted: April 6, 2016 Online Published: April 29, 2016

doi:10.5539/gjhs.v8n12p141

URL: http://dx.doi.org/10.5539/gjhs.v8n12p141

\begin{abstract}
The purpose of this study was to assess the knowledge and attitude of primary school teachers in Tehran (Iran) towards attention deficit hyperactivity disorder (ADHD) and specific learning disability (SLD). This study was conducted on 205 primary school teachers in Tehran. Using multi-stage sampling, 25 schools were selected randomly. The selected teachers completed a self-report questionnaire on knowledge and attitude towards ADHD and SLD. They were found to have average knowledge of as well as mostly neutral attitudes towards SLD and ADHD. There was a positive significant relationship between knowledge and attitude scores of the participants on the two disorders. Regarding students with ADHD or SLD, instead of referring to specialists, most teachers chose to inform the parents. Our findings mainly indicate average knowledge and attitude scores for both ADHD and SLD-compared to lower findings in previous studies. Those responsible for organizing and holding in-service training workshops on these issues need to have complete mastery and up-to-date information. It is necessary that the results of such studies be used in educational planning and policy making in the Ministry of Education.
\end{abstract}

Keywords: attention deficit disorder with hyperactivity, special learning disability, teachers, knowledge, attitude, practice

\section{Introduction}

As in many other countries, nearly ten percent of Iranian children suffer from attention deficit hyperactivity disorder (ADHD), which is defined as a persistent pattern of inattention or impulsivity that is formed during growth (Ghanizadeh, 2008). It is manifested in two or more contexts (e.g., at home, school or work) and negatively affects the individual's social, academic or occupational functioning. ADHD is usually co-occur with SLD, aggression, poor relationship with peers, disregard or disobedience of orders, high risk-taking, low self-esteem, depression, and social, emotional and cognitive problems (Raskind, 2005). This disorder leads to obvious dysfunction among children, with educational performance being the most important function to suffer (B. J. Sadock \& V. A. Sadock, 2010). Children with ADHD often experience problems in interpersonal and academic relationships, which are typically caused by insufficient attention to homework, impulsive behaviors, and difficulty in controlling excitement (Bekle, 2004; B. J. Sadock \& V. A. Sadock, 2010). Previous studies indicate that teachers seem to share many misconceptions about ADHD (Murray, 2010). Generally, studies in this field in Iran and other countries show a lack of desirable knowledge and attitudes (Alkahtani, 2013; Anderson, Watt, \& Shanley, 2013; Blotnicky-Gallant, Martin, McGonnell, \& Corkum, 2014; Brook, Watemberg, \& Geva, 2000; Ghanizadeh, Bahredar, \& Moeini, 2006; Jimoh, 2014; Perold, Louw, \& Kleynhans, 2010; Rodrigo, Perera, Eranga, Williams, \& Kuruppuarachchi, 2011; Salamatbakhsh et al., 2016; Snider, Busch, \& Arrowood, 2003).

ADHD can be comorbid with many other psychiatric problems including specific learning disabilities (SLD) (DuPaul, Gormley, \& Laracy, 2012). SLD includes learning difficulty in foreign languages, and the inability to draw shapes, calculate, read, and write. The incidence of SLD was reported as ranging from 5\% to $15 \%$ in 2013 
by the American Psychological Association (Association, 2013). According to DSM-5, SLD leads to disorders in learning or using specific educational skills (such as reading, writing or mathematics), which form the basis of academic learning. Although children with SLD have normal IQ and no physical problems, they exhibit clearly lower levels of performance when compared to other students. SLD may lead to a host of educational problems. In order to fully understand SLD, the social, emotional and behavioral areas of children's lives need to be considered (Peters, 2011) a point that is neglected by most teachers (Mogasale, Patil, Patil, \& Mogasale, 2012). If the disorder is not diagnosed and treated properly, the risk of developing other problems like depression, stress and delinquency increases. A correlation between knowledge and supportive behaviors towards SLD students has been found (Murray, 2010).

The educational life of children is affected by both ADHD and SLD (Ghanizadeh et al., 2006; B. J. Sadock \& V. A. Sadock, 2010), which are comorbid in up to $50 \%$ of cases (DuPaul et al., 2012). Teachers are usually the first to recognize it in their students (Nolan, Gadow, \& Sprafkin, 2001). As students spend most of their time at school and are in close relationships with their teachers, they are in the best position to recognize such children and refer them to specialized centers. The diagnosis of SLD, especially in primary schools, can prove to be an effective step in treating the disorder. Considering the substantial number of students suffering from SLD, especially in primary schools, teachers must be trained to recognize these students in their classes to provide them with proper and timely education as well as necessary rehabilitation measures (Trute, Worthington, \& Hiebert-Murphy, 2008).

Lack of sufficient knowledge and improper attitudes by teachers may have irreversible effects, whereas a conscious attitude with tolerance and encouragement by teachers can improve low self-esteem, social isolation and deprivation of rights in these children (Ghanizadeh, Fallahi, \& Akhondzadeh, 2009). Thus, proper awareness of and attitude towards ADHD and SLD are extremely important, especially among teachers. To the best of our knowledge, this is the first study to simultaneously consider knowledge of and attitudes towards these disorders among primary school teachers. Furthermore, cultural issues should be considered in relation to knowledge and attitude.

This study aims to investigate the knowledge and attitudes of primary school teachers in Tehran regarding ADHD and SLD.

\section{Methods}

This is a cross sectional study, which was conducted on Tehrani primary school teachers who were selected in multi-stage sampling. The city of Tehran was divided into five districts: North, South, East, West, and Center. From each district, five schools were chosen at random, yielding a total of 25 .

The study population included all primary school teachers in Tehran/Iran with at least one year of teaching experience. Teachers who did not fill out the questionnaires completely, as well as those who did not want to participate were excluded. The participants were approached by the researchers, who explained the project, provided plain language statements (PLSs), and answered their queries. They were assured that their decision regarding participation would not affect anything at school. Those who agreed to participate signed an informed consent form, and were given three self-report questionnaires (demographic information, knowledge of and attitudes toward SLD, and knowledge of and attitudes towards ADHD) which were set to return later in a sealed envelope to the researchers. Each case needed 10-15 minutes to fill out the questionnaires. Approximately eight teachers from each school entered the study. All participants received an ID enabling them to withdraw their information should they change their mind about participating. A total of 223 questionnaires were distributed in the selected schools of Tehran from October 2013 to June 2014, and 205 teachers filled out and returned the questionnaires.

A self-report questionnaire was used in this study comprising three parts: (1) demographic questions covering age, gender, education, and training experience of the participants. In the second part, we asked if the teacher had students with ADHD or SLD, and what was her/his reaction to the problem of those students. (2) Knowledge and Attitude about ADHD: This questionnaire includes two parts: A) 33 knowledge questions with true/false/do not know answers. It has sub-scales in the field of development of disorders, symptoms (attention deficit, hyperactivity, and impulsivity), identification of suffering children, attending to similar clinical disorders, prognosis and treatment (low, average, and high), B) 13 attitude questions with strongly disagree/disagree/neutral/agree/strongly agree answers (negative, neutral, and positive attitudes). (3) and Attitude about SLD: This questionnaire includes two parts: A) knowledge part that surveys the overall knowledge and typology of SLD. It has 26 questions with true/false/do not know answers (low, average, and high), and B) attitude part that has 8 questions with strongly disagree/disagree/neutral/agree/strongly agree 
answers (negative, neutral, and positive attitudes). Samples of questions in each part are presented in Appendix A.

In order to develop the questionnaire, DSM-IV-TR in addition to previous works having similar topics and methods to those of this study were considered (APA, 2000; Brook et al., 2000; Ghanizadeh et al., 2006). The questionnaire was developed by the authors, with the items being originally proposed using from the aforementioned sources. Once the items were finalized, they were reviewed and confirmed by five child psychiatrists and education specialists, thus proving the questionnaire's face validity. In next step, a pilot study on a small population of teachers $(\mathrm{n}=20)$ was conducted to confirm the feasibility of administration/conceptual clarification. To determine test-retest reliability, it was administered those 20 teachers again after two weeks, and the repeatability index of the questionnaire was estimated 0.8 which is adequate (George, 2003). Subsequently, the internal consistency of the questionnaire was examined using Cronbach's alpha coefficient, yielding 0.82 , indicating good internal consistency; this means that the instrument presents similar related items as well as unique information in each item (Peters, 2014). The results from those 20 initial questionnaires were not included in the main data analysis.

In case of $\mathrm{d}=0.8$, the sample size formula was:

$$
N=\frac{z^{2} \times \sigma}{d^{2}}=\frac{(1.96)^{2} \times 2}{2}=\frac{4}{8}=200
$$

Permission to carry out the study was officially obtained from the Ministry of Education. The study was approved by the Ethical Review Board of the Behavioral Sciences Research Center of Shahid Beheshti University of Medical Sciences, Tehran, Iran (No.6455). Informed consent forms were obtained from all participants. Prior to study, during a formal session held separately at each school, the participants were provided with a general overview of the goals and aspects of the study. They were also informed that their participation is voluntarily, and that they may choose to leave the study at any time without any negative consequences. The results were used anonymously, and all of the data were kept confidential.

The SPSS software package was used for data analysis. Chi-square method and Cronbach's alpha were applied to examine the validity and reliability of the questionnaires developed by the authors (knowledge of and attitudes toward SLD, and knowledge of and attitudes toward ADHD). Also, the process of test or categorization of variables in classes calculated through Chi-square test. Inferential statistics including repeated measures analysis of variance (ANOVA) and paired samples t-test were used to analyze the data extracted from the questionnaires.

\section{Results}

Table 1 presents the demographic information of participants. Moreover, Figure 1 shows what actions teachers are likely to take when they recognize students with ADHD and SLD.

Table 1. Frequency and percent of gender, degree and teaching experience in teachers

\begin{tabular}{llll}
\hline & & $\mathrm{N}$ & $\%$ \\
\hline \multirow{2}{*}{ Gender } & Female & 178 & 86.8 \\
& Male & 27 & 13.2 \\
Degree & Diploma & 79 & 38.5 \\
& Bachelor & 124 & 60.5 \\
Teaching experience & Master & 2 & 1.0 \\
& 10 yrs $<$ & 62 & 30.2 \\
Experience of having students with SLD & $>10$ yrs & 143 & 69.8 \\
Experience of having students & Yes & 166 & 81.0 \\
with ADHD & No & 25 & 12.2 \\
\hline
\end{tabular}




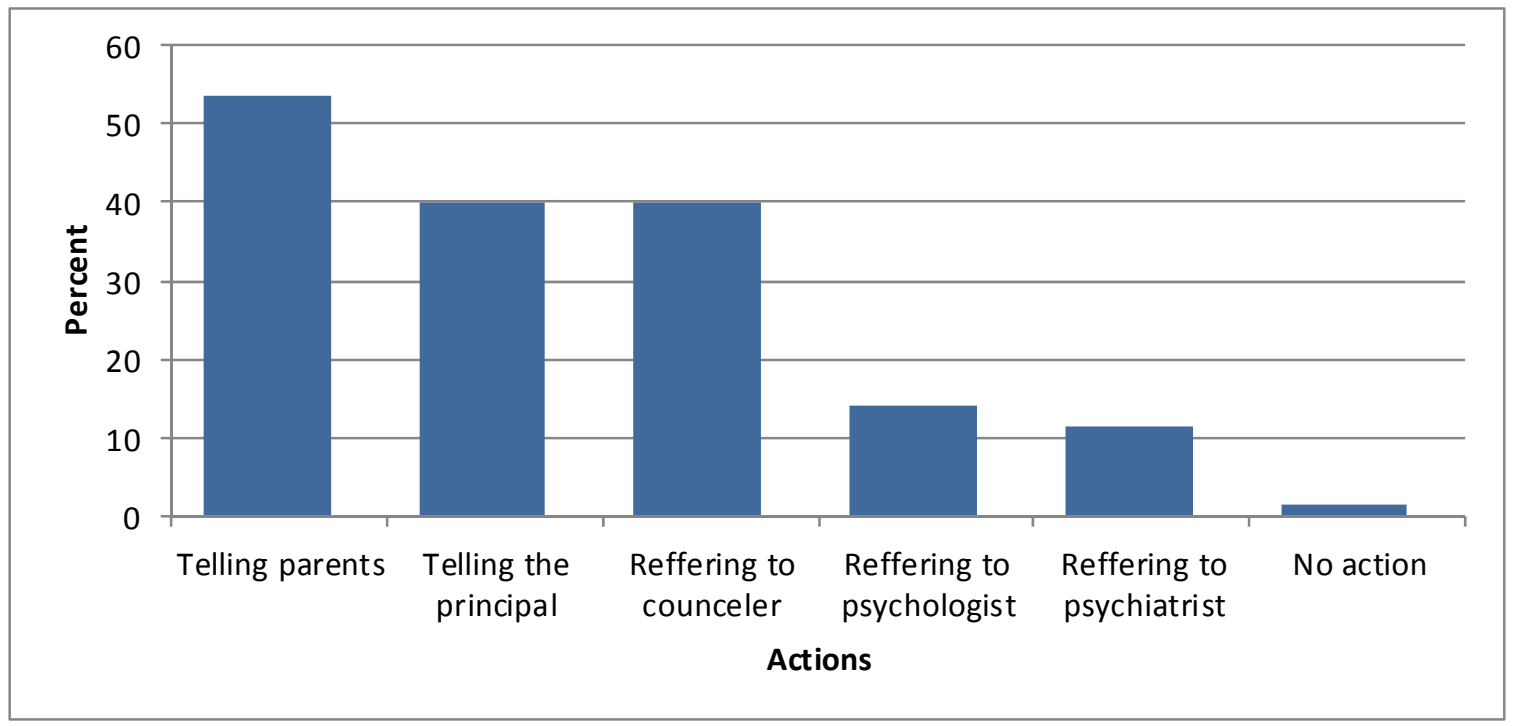

Figure 1. Frequency of actions taken by teachers in case of recognizing a student with ADHD or SLD

The sources of information about ADHD and SLD used by different teachers are listed in Table 2.

Table 2. Sources of information about ADHD and SLD

\begin{tabular}{lllll}
\hline & ADHD & \multicolumn{2}{l}{ SLD } \\
\hline & $\mathrm{N}$ & $\%$ & $\mathrm{~N}$ & $\%$ \\
\hline Colleagues & 55 & 27.5 & 51 & 25.5 \\
Conferences and in-service training & 55 & 27.5 & 50 & 25 \\
Specialized books and articles & 50 & 25 & 41 & 20 \\
Radio and TV & 47 & 23.5 & 31 & 15.5 \\
University & 42 & 21 & 40 & 20 \\
Internet & 35 & 17.5 & 33 & 16.5 \\
Friends and family & 28 & 14 & 31 & 15.5 \\
Newspaper & 27 & 13.5 & 20 & 10 \\
Psychiatrists and psychologists & 26 & 13 & 33 & 16.5 \\
\hline
\end{tabular}

For both SLD and ADHD, information is most frequently obtained from colleagues as well as conferences and in-service training.

The distribution of the overall teachers' knowledge of and attitude toward ADHD and SLD is presented in Table 3.

Table 3. Distribution of the overall teachers' knowledge of and attitude toward ADHD and SLD

\begin{tabular}{llll}
\hline & & Mean & $\%$ \\
\hline (Knowledge) ADHD & Low & 10 & 6.3 \\
& Medium & 141 & 88.7 \\
& High & 8 & 5.0 \\
(Knowledge) SLD & Total & $\mathbf{1 5 9}$ & $\mathbf{1 0 0 . 0}$ \\
& Low & 35 & 18.6 \\
& Medium & 83 & 44.1 \\
& High & 70 & 37.2 \\
\hline
\end{tabular}




\begin{tabular}{llll}
\hline & Total & $\mathbf{1 8 8}$ & $\mathbf{1 0 0 . 0}$ \\
(Attitude) ADHD & Neutral & 99 & 65.1 \\
& Positive & 93 & 48.4 \\
& Negative & 0 & 0 \\
& Total & $\mathbf{1 9 2}$ & $\mathbf{1 0 0 . 0}$ \\
& Neutral & 98 & 47.6 \\
& Positive & 91 & 35.1 \\
& Negative & 2 & 10.0 \\
& Total & $\mathbf{1 9 1}$ & $\mathbf{1 0 0 . 0}$ \\
\hline
\end{tabular}

Table 4 shows the means and standard deviations values in Table 3.

Table 4. The mean and standard deviation of the teacher's overall knowledge and attitude

\begin{tabular}{lllll}
\hline & & Max & Mean & sd \\
\hline Knowledge of ADHD & & 33 & 17.28 & 3.9 \\
Attitude towards ADHD & & 39 & 18.51 & 2.8 \\
Knowledge of SLD & One (overall knowledge) & 7 & 3.13 & 1.3 \\
& Two (types, typology) & 19 & 11.97 & 5.55 \\
Attitude towards SLD & & 24 & 10.71 & 2.1 \\
\hline
\end{tabular}

Finally, the correlation between the scores on knowledge and attitude in each disorder and between the two disorders can be seen in Table 5 .

Table 5. Correlation between the teacher's scores on knowledge and attitude

\begin{tabular}{lllll}
\hline \multicolumn{4}{l}{ Attitude towards SLD } & \multicolumn{4}{l}{ Knowledge of ADHD } \\
\hline P value & $\mathrm{r}$ & $\mathrm{P}$ value & $\mathrm{r}$ & \\
\hline$* 0.016$ & 0.179 & 0.112 & 0.128 & Attitude towards ADHD \\
0.359 & 0.069 & $* * 0.0000$ & 0.397 & Knowledge of SLD \\
\hline
\end{tabular}

$* \mathrm{P}<0 / 05 ; * * \mathrm{P}<0 / 0001$

There was a positive significant relationship between knowledge $(\mathrm{r}=0.397, \mathrm{P}<0 / 0001)$ and attitude $(\mathrm{r}=0.179$, $\mathrm{P}=0.016$ ) of teachers about ADHD and SLD. In other words, teachers with more knowledge of ADHD had significantly more knowledge of SLD. A positive significant relationship was also found between attitudes towards SLD and ADHD.

\subsection{Knowledge of and Attitude towards ADHD}

One-fourth of the teachers thought that sugar and additives can be the reason behind ADHD. Nearly one quarter (26.2\%) of the teachers reported that ADHD in children is caused by both genetics and upbringing while $24.6 \%$ believed that ADHD is caused by improper upbringing. The majority $(67.3 \%)$ of the teachers believed that, in terms of IQ, students with ADHD are similar to normal students. The children were expected to be driven towards some sort of addiction in adulthood by $42 \%$ of the teachers. Furthermore, $77.7 \%$ said that ADHD may cause students to drop out of school and $66 \%$ were aware of the possibility of delinquency in children with ADHD.

Eighty-three percent of the teachers were aware of the fact that ADHD can be treated with medication and $84.6 \%$ considered medication for the children with ADHD necessary. However, $25 \%$ of them thought that long-term use of medication increases the risk of addiction in adulthood for children with ADHD. Placing ADHD students in special schools was thought to be a viable solution by $39.7 \%$ of the teachers. Although $95.5 \%$ thought that these children need more psychological support, only $32.7 \%$ agreed to assign simpler homework to these children. Finally, nearly all teachers (97\%) stated that working with those children requires much energy. 


\subsection{Knowledge of and Attitude towards SLD}

A positive significant relationship was found between the knowledge of teachers in different forms of SLD (mathematics and reading and writing) with a correlation of $0.711(\mathrm{P}<0.0001)$. Genetics, as opposed to upbringing was considered to be the primary cause of SLD (11.1\% vs. $73.5 \%$, respectively). Furthermore, $26.1 \%$ of the teachers stated that SLD seems to gradually improve with age.

Nearly half (50.5\%) said that students with SLD have lower IQ compared to normal students. Only a small proportion of the participants $(11.7 \%$ ) agreed with tutoring these children whereas $62 \%$ thought that they should be demoted to lower grades. Finally, $85.9 \%$ believed that children with SLD should visit psychiatrists.

\section{Discussion and Conclusion}

Simultaneous measurement of knowledge of and attitudes toward two common childhood mental disorders with significant comorbidity rate is an important feature of this study. Most importantly, our findings indicate average knowledge and attitude scores for both ADHD and SLD. Compared with SLD, more studies have been conducted on knowledge of and attitude towards ADHD. Teachers have been found to have only basic knowledge of ADHD in Puerto Rico (González, González, Ramírez, \& Rivera, 2008), Nigeria (Jimoh, 2014), and Africa (Perold et al., 2010); this was also true for general practitioners (GP) and pediatricians in Pakistan (Jawaid et al., 2008). Knowledge levels were shown to be lower than the desirable in Bahrain (Trute et al., 2008) and insufficient in Saudi Arabia (Alkahtani, 2013). Average ADHD awareness has been reported among teachers in Canada (Blotnicky-Gallant et al., 2014) and Iran (Ghanizadeh et al., 2006), as opposed to desirable in Vienna/Austria (Schweifer, 2009). Our study was in line with recent studies in Iran and Canada. It seems that cultural and regional factors have influenced these results. According to the results, the participants had more knowledge about typology of ADHD, which is consistent with findings in Puerto Rico (González et al., 2008). Regarding SLD, $44 \%$ of the teachers had average knowledge, compared to $37 \%$ with adequate knowledge. Few studies have been carried out to investigate knowledge of and attitude towards SLD. In an Iranian study (Kakabaraee, Arjmandnia, \& Afrooz, 2012), acceptable knowledge of the etiology and nature of SLD and extremely insufficient knowledge of diagnosis and typology were reported. In a study on GPs and pediatricians in Pakistan, the two disorders were investigated using a self-administered questionnaire. According to the results, the participants showed extremely insufficient knowledge to effectively screen or diagnose ADHD and SLD (Jawaid et al., 2008). In our study, $10 \%$ of the teachers had no knowledge of SLD symptoms. The vast majority of the teachers were aware of the definition of SLD whereby students experience difficulties in reading, writing or mathematics compared to their intelligence level. More than half of the teachers had neutral attitudes toward ADHD and SLD. Since teachers generally expect their students to get high scores, these results seem somewhat foreseeable in that these children are less likely to be assessed as positive.

Another finding of this study was the positive significant relationship between the teachers' knowledge of ADHD and that of SLD and as well as the relationship between their attitudes toward ADHD and SLD. Because these two are prevalent and highly comorbid childhood disorders, it is predicted that teachers with better knowledge of and attitude towards one will have better knowledge of and attitude towards the other. This can be justified by considering their high comorbidity and overlap of the symptoms (DuPaul et al., 2012; Kutscher, 2014; Mayes, Calhoun, \& Crowell, 2000).

In our study, less than one-third of the participants believed that ADHD and SLD lessen with age. Despite the fact that the vast majority of teachers were aware of alternative medical treatment and its drastic effect on concentration, only $11 \%$ refer students to receive proper treatment by professionals (psychiatrist and psychologist). This means that mere knowledge about the effectiveness of medical treatment is not sufficient to prompt a referral. Only 37\% were aware of medical treatment in Brook et al.'s (2000) and 85\% in Ghanizadeh et al.'s. In a Canadian study (Blotnicky-Gallant et al., 2014), a significant number of teachers disagreed with using medicine (giving various reasons such as "taking medicine intervenes with growth" or "students are too young to take medicine", "medicine is not necessary" or "it should not be taken"). Fortunately, an increasing trend of teachers' awareness about medical treatment of ADHD has emerged in Iran since 2006 (Ghanizadeh et al., 2006). Also, geographical differences may influence the results in different studies. All these demonstrate that teachers are confused about how to behave toward and teach these children and are unaware of their special instructional needs such as medication and occupational therapy.

In a study by Brook et al., about one fifth of the teachers were aware of the high risk of delinquent behaviors in adolescence (Brook et al., 2000). A similar Iranian study reported awareness of higher than 50\% (Ghanizadeh et al., 2009). In our study, awareness $66 \%$, and $77 \%$ of the teachers were aware of the possibility of dropout from school, which is two times more than what was reported by Ghanizadeh et al. (2009). This is indicative of 
increased awareness among teachers about the symptoms and consequences of ADHD in recent years.

More than half of the population believed that ADHD is caused by improper upbringing. This finding is in line with a study in Sri Lanka, wherein over $80 \%$ of primary school teachers assumed that parents are to blame if their children suffer from ADHD (Rodrigo et al., 2011). In a study in Iran, the greater portion of teachers attributed the disorder to parenting style (Ghanizadeh et al., 2006). Contrarily, in this study, the general consensus (73\%) was that genetics play a role in ADHD. Teachers were deemed to have acceptable knowledge about the nature and etiology of SLD. There was a significant relationship between the scores on reading, writing and mathematics disorders, implying that teachers with more information on reading and writing had more information on SLD in mathematics as reported before (Kakabaraee et al., 2012).

As mentioned earlier, conferences and in-service training are the primary sources of information about ADHD/SLD for teachers; this finding is in agreement with those of Jawaid et al. on GPs (Jawaid et al., 2008). Thus, the Ministry of Education needs to take a more proactive approach by designing and conducting specialized in-service training courses for primary school teachers in order to increase recognition and encourage referring ADHD/SLD children to specialized centers. Also Jawaid (2008) reported that participants who read medical journals or participated in seminars were slightly more knowledgeable in this area (Jawaid et al., 2008). As discussed, in comparison with previous works, Iranian teachers obtained slightly higher knowledge and attitude scores on ADHD. This relative increase can be attributed to the new sources of information such as conferences and in-service training, in addition to specialized books and articles, consistent with Ghanizadeh et al. (2006) who reported newspapers and magazines as the primary sources of information. Yet, the fact that the last alternative of teachers is referring to psychologists and psychiatrists is due to the spectrum of knowledge and action, future studies should mind bridging the gap between knowledge and decisions in teachers.

We recommend that educational interventions be intended to improve the knowledge, attitude and behavior of the teachers, and the results be assessed in the long run (Khademi, Safai, Davari Ashtiani, Panaghi, \& Noorbakhsh, 2015; Moldavsky \& Sayal, 2013). As shown, a significant relationship exists between knowledge and attitude towards these two disorders. Other aspects of the relationship need to be investigated in future studies. Regarding the dearth of these kinds of studies in Iran and considerable incidence of SLD future studies should be conducted, especially in the area of SLD. In addition, conducting other studies aiming at the simultaneous assessment of knowledge of and attitude towards SLD and ADHD seems necessary considering the comorbidity of these two disorders, as well as their relationship with each other. Based on results of this study and the significant impact of these disorders in the lives of children, teachers need to be trained by experts with up-to-date information. Furthermore, discussion and interaction are required for changing one's opinions; thus, it is recommended that training sessions be in the form of instructional workshops. It is necessary that the results of this study and other similar studies be used in educational planning and policy making in the Ministry of Education.

The main finding of the current study was that teachers achieved average scores for knowledge of and attitude toward both SLD and ADHD. Also, there was a positive relationship between the teacher's knowledge of ADHD with that of SLD, and between their attitudes toward ADHD and SLD. Finally, for the most part, teachers receive information about ADHD/SLD from conferences and in-service training as well as their colleagues.

To the best of our knowledge, there is no study which simultaneously considers primary school teachers' knowledge of and attitude towards ADHD and SLD, or even SLD. This study includes comprehensive coverage of the relevant literature, ethically approved data collection, professionally analyzed data, and finally, an inspirational discussion. According to our results, lack of sufficient knowledge and improper attitude by teachers can have irreversible effects on academic and social life of children with SLD and ADHD, while a conscious attitude with tolerance and encouragement by teachers can improve low self-esteem, social isolation, and deprivation of rights in these children. Thus, proper awareness and attitude towards ADHD and SLD are very important, especially among teachers. To our knowledge, there is no report in the literature simultaneously investigating ADHD and on primary school teachers. Furthermore, cultural issues should be considered in relation to knowledge and attitude.

\section{Acknowledgements}

The authors are thankful to all the teachers who made this study possible by their active participation.

\section{Role of Funding and Conflict of Interest}

This work was funded in part by Behavioral Sciences Research Center (BSRC) of Shahid Beheshti University of Medical Sciences (No. 6455). The funding source had no involvement in study design; in the collection, analysis 
and interpretation of data; in the writing of the report; and in the decision to submit the paper for publication.

\section{Competing Interests Statement}

The authors declare that there is no conflict of interests regarding the publication of this paper.

\section{References}

Alkahtani, K. D. (2013). Teachers' Knowledge and Misconceptions of Attention Deficit/Hyperactivity Disorder. Psychology, 4(12), 963. http://dx.doi.org/10.4236/psych.2013.412139

Anderson, D. L., Watt, S. E., \& Shanley, D. C. (2013). A multi-dimensional model of the origins of attitude certainty: Teachers' attitudes toward attention-deficit/hyperactivity disorder. Social Psychology of Education, 17(1), 19-50. http://dx.doi.org/10.1007/s11218-013-9235-5

APA. (2000). Diagnostic and statistical manual-text revision (DSM-IV-TRim, 2000): American Psychiatric Association.

Association, A. P. (2013). DSM 5: American Psychiatric Association.

Bekle, B. (2004). Knowledge and attitudes about attention-deficit hyperactivity disorder (ADHD): A comparison between practicing teachers and undergraduate education students. Journal of Attention Disorders, 7(3), 151-161. http://dx.doi.org/10.1177/108705470400700303

Blotnicky-Gallant, P., Martin, C., McGonnell, M., \& Corkum, P. (2014). Nova Scotia Teachers' ADHD Knowledge, Beliefs, and Classroom Management Practices. Canadian Journal of School Psychology, 0829573514542225.

Brook, U., Watemberg, N., \& Geva, D. (2000). Attitude and knowledge of attention deficit hyperactivity disorder and learning disability among high school teachers. Patient Education and Counseling, 40(3), 247-252. http://dx.doi.org/10.1016/S0738-3991(99)00080-4

DuPaul, G. J., Gormley, M. J., \& Laracy, S. D. (2012). Comorbidity of LD and ADHD: Implications of DSM-5 for assessment and treatment. Journal of Learning Disabilities, 0022219412464351.

George, D. (2003). SPSS for windows step by step: A simple study guide and reference. 17.0 update, 10/e: Pearson Education India.

Ghanizadeh, A. (2008). Distribution of symptoms of attention deficit-hyperactivity disorder in schoolchildren of Shiraz, south of Iran. Arch Iran Med, 11(6), 618-624.

Ghanizadeh, A., Bahredar, M. J., \& Moeini, S. R. (2006). Knowledge and attitudes towards attention deficit hyperactivity disorder among elementary school teachers. Patient Education and Counseling, 63(1), 84-88. http://dx.doi.org/10.1016/j.pec.2005.09.002

Ghanizadeh, A., Fallahi, M., \& Akhondzadeh, S. (2009). Disclosure of Attention Deficit Hyperactivity Disorder and its Effect on Rejection of Students by Teachers. Iranian Journal of Medical Sciences, 34(4).

González, T. G., González, M., Ramírez, B., \& Rivera, M. (2008). Attention deficit hyperactivity disorder in five schools of the San Juan metropolitan area: Assesment of teacher's knowledge. Boletin de la Asociacion Medica de Puerto Rico, 101(1), 31-35.

Jawaid, A., Zafar, A., Naveed, A., Sheikh, S., Waheed, S., Zafar, M., ... Fatmi, Z. (2008). Knowledge of primary paediatric care providers regarding attention deficit hyperactivity disorder and learning disorder: A study from Pakistan. Singapore Medical Journal, 49(12), 985.

Jimoh, M. (2014). Knowledge and Attitudes towards Attention Deficit Hyperactivity Disorder among Primary School Teachers in Lagos State, Nigeria. Advances in Life Science and Technology, 23, 7-15.

Kakabaraee, K., Arjmandnia, A. A., \& Afrooz, G. A. (2012). The study of awareness and capability of primary school teachers in identifying students with learning disability in the province of Kermanshah. Procedia-Social and Behavioral Sciences, 46, 2615-2619. http://dx.doi.org/10.1016/j.sbspro.2012.05.534

Khademi, M., Safai, N., Davari Ashtiani, R., Panaghi, L., \& Noorbakhsh, S. (2015). Comparison of Effect of Workshop and Training Package Teaching Methods on Changing Primary School Teachers' Knowledge and Attitudes toward Attention Deficit Hyperactivity Disorder. American Journal of Life Science Researches. Under Press.

Kutscher, M. L. (2014). Kids in the Syndrome Mix of ADHD, LD, Autism Spectrum, Tourette's, Anxiety, and More!: The one-stop guide for parents, teachers, and other professionals. Jessica Kingsley Publishers. 
Mayes, S. D., Calhoun, S. L., \& Crowell, E. W. (2000). Learning disabilities and ADHD overlapping spectrum disorders. Journal of Learning Disabilities, 33(5), 417-424. http://dx.doi.org/10.1177/002221940003300502

Mogasale, V. V., Patil, V. D., Patil, N. M., \& Mogasale, V. (2012). Prevalence of specific learning disabilities among primary school children in a South Indian city. The Indian Journal of Pediatrics, 79(3), 342-347. http://dx.doi.org/10.1007/s12098-011-0553-3

Moldavsky, M., \& Sayal, K. (2013). Knowledge and Attitudes about Attention-Deficit/Hyperactivity Disorder (ADHD) and its Treatment: The Views of Children, Adolescents, Parents, Teachers and Healthcare Professionals. Current psychiatry reports, 15(8), 1-7. http://dx.doi.org/10.1007/s11920-013-0377-0

Murray, E. (2010). "Don't give up on them": Managing Attention Deficit Hyperactivity Disorder in Schools-What teachers and parents believe and know. Murdoch University. Retrieved from http://researchrepository.murdoch.edu.au/id/eprint/1667

Nolan, E. E., Gadow, K. D., \& Sprafkin, J. (2001). Teacher reports of DSM-IV ADHD, ODD, and CD symptoms in schoolchildren. Journal of the American Academy of Child \& Adolescent Psychiatry, 40(2), 241-249. http://dx.doi.org/10.1097/00004583-200102000-00020

Perold, M., Louw, C., \& Kleynhans, S. (2010). Primary school teachers' knowledge and misperceptions of attention deficit hyperactivity disorder (ADHD). South African Journal of Education, 30(3), 0-0.

Peters, G.-J. Y. (2014). The alpha and the omega of scale reliability and validity: Why and how to abandon Cronbach's alpha and the route towards more comprehensive assessment of scale quality. European Health Psychologist, 16(2), 56-69.

Peters, J. (2011). Transition Skills of First-Year College Students with Learning Disabilities. ProQuest LLC.

Raskind, M. (2005). Research trends: Social information processing and emotional understanding in children with LD. Journal of Learning Disabilities, 38, 190.

Rodrigo, M., Perera, D., Eranga, V., Williams, S., \& Kuruppuarachchi, K. (2011). The knowledge and attitude of primary school teachers in Sri Lanka towards childhood attention deficit hyperactivity disorder. Ceylon Medical Journal, (56), 51-54. http://dx.doi.org/10.4038/cmj.v56i2.3108

Sadock, B. J., \& Sadock, V. A. (2010). Kaplan and Sadock's pocket handbook of clinical psychiatry. Lippincott Williams \& Wilkins.

Salamatbakhsh, N., Khademi, M., Noorbakhsh, S., Rajeziesfahani, S., Davari-Ashtiani, R., \& Razjouyan, K. (2016). Investigating the Knowledge and Attitude of Primary School Teachers in Tehran towards Attention-Deficit/Hyperactivity and Learning Disorders and Relation to Teacher's Characteristics. Scientific Journal of Rehabilitation Medicine, 5(3), Under Press.

Schweifer, C. (2009). Attention deficit and hyperactivity in school children--knowledge, resources and cooperation among professions concerned. Wien Med Wochenschr, 159(7-8), 183-187. http://dx.doi.org/10. 1007/s10354-009-0668-6

Snider, V. E., Busch, T., \& Arrowood, L. (2003). Teacher knowledge of stimulant medication and ADHD. Remedial and Special Education, 24(1), 46-56. http://dx.doi.org/10.1177/074193250302400105

Trute, B., Worthington, C., \& Hiebert-Murphy, D. (2008). Grandmother support for parents of children with disabilities: Gender differences in parenting stress. Families, Systems, \& Health, 26(2), 135. http://dx.doi. org/10.1037/1091-7527.26.2.135

\section{Appendix A}

ADHD and SLD Knowledge, Attitude and Practice

Please answer all the questions. There is no right or wrong answer. Please do not write your name.

Thank you very much for your time and consideration.

Gender:

Male

$\square$ Female

Educational qualification:

Which grade are you teaching? 
Teaching experience: ... years

Have you ever taught to students with ADHD? $\square$ Yes $\square$ No

Have you ever taught to students with SLD? $\square$ Yes $\square$ No

In case of presence of a student with ADHD or SLD in the class, what action would you take? You may choose more than one option.

$\square$ Referring to psychiatrist, $\square$ Referring to psychologist, $\square$ Referring to counselor, $\square$ Informing the parents,

$\square$ Informing the school authorities, $\square$ No action, $\square$ Other actions ...

From what sources do you obtain information about ADHD? You may choose more than one option.

$\square$ Books and specialized articles, $\square$ Media (radio, TV, newspaper, magazines, etc.), $\square$ Internet, $\square$ Colleague

$\square$ Conferences and in-service trainings, $\square$ University educational materials, $\square$ Specialists (psychiatrist, psychologist)

$\square$ Other people (friends, family members, etc.)

From what sources did you achieve information about SLD? You may choose more than one option.

$\square$ Books and specialized articles, $\square$ Media (radio, TV, newspaper, magazines, etc.), $\square$ Internet, $\square$ Colleague

$\square$ Conferences and in-service trainings, $\square$ University educational materials, $\square$ Specialists (psychiatrist and psychologists)

$\square$ Others (friends, family members, etc.)

*In the fallowing part, 5 sample questions of each questionnaire are presented.

Please score your opinion and attitude toward ADHD using the following key:

1=strongly disagree, $2=$ disagree, $3=$ neutral, $4=$ agree, $5=$ strongly agree

\begin{tabular}{|l|l|l|l|l|l|}
\hline ADHD & 1 & 2 & 3 & 4 & 5 \\
\hline Students with ADHD have similar IQ as normal ones. & & & & & \\
\hline Students with ADHD need more psychological support. & & & & & \\
\hline If they receive appropriate treatment, they can go to university like any other student. & & & & & \\
\hline In adulthood, many of them will be drawn into drug addiction. & & & & & \\
\hline Their parents lack adequate parenting skills. & & & & \\
\hline
\end{tabular}

\begin{tabular}{|l|l|l|l|l|l|}
\hline SLD & 1 & 2 & 3 & 4 & 5 \\
\hline Children with SLD should be given easier homework and exams. & & & & & \\
\hline They should be given more time to complete exams. & & & & & \\
\hline They should be allowed to take oral, rather than written, tests. & & & & \\
\hline They should be placed in separate specialized classrooms. & & & & \\
\hline These children can have a university education like other students. & & & & \\
\hline
\end{tabular}

The following statements are about children with ADHD. Please mark the appropriate option in each sentence. Please answer all questions, and mark "do not know" if you are unsure about it.

$1=$ true, $2=$ false, $3=$ do not know

\begin{tabular}{|l|l|l|l|}
\hline ADHD & 1 & 2 & 3 \\
\hline
\end{tabular}




\begin{tabular}{|l|l|l|}
\hline About $7 \%$ to $12 \%$ of students suffer from ADHD. & & \\
\hline ADHD rate is equal in girls and boys. & & \\
\hline The disorder normally begins after the age of 7. & & \\
\hline Their family members are more likely to suffer from ADHD compared to those of normal children. & & \\
\hline ADHD is mainly due to genetic problems. & & \\
\hline
\end{tabular}

The following statements are about children with SLD. Please mark the appropriate option in each sentence. Please answer all questions, and mark "do not know" if you are unsure about it.

$1=$ true, $2=$ false, $3=$ do not know

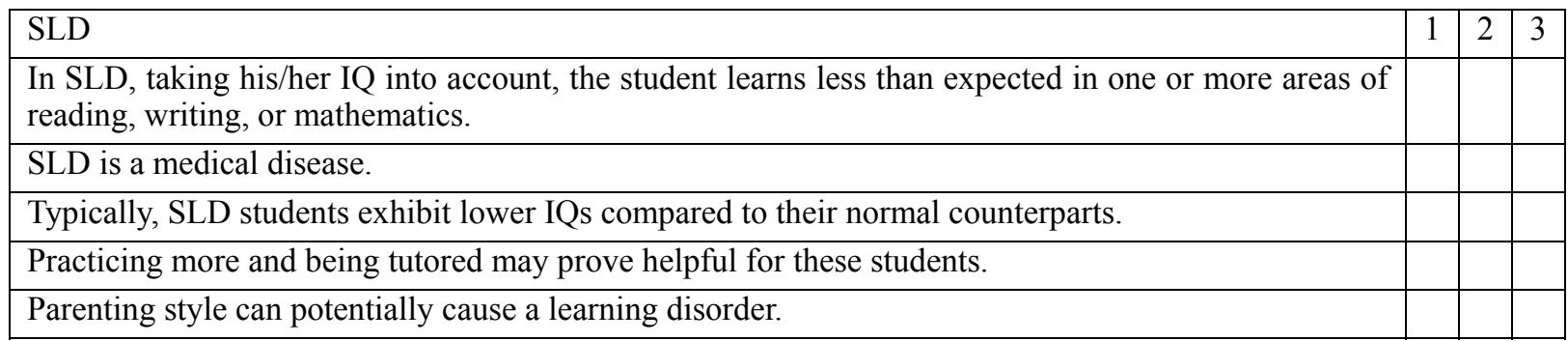

\section{Copyrights}

Copyright for this article is retained by the author(s), with first publication rights granted to the journal.

This is an open-access article distributed under the terms and conditions of the Creative Commons Attribution license (http://creativecommons.org/licenses/by/3.0/). 